\title{
EVALUATION THE EFFICIENCY OF NANO SEASHELL, SODIUM FLUORIDE AND COMMERCIALLY AVAILABLE TOOTHPASTE ON DENTINAL TUBULES OCCLUSION AFTER ACID ATTACK USING SCANNING ELECTRON MICROSCOPE: IN VITRO STUDY
}

\author{
Reem Ashraf* $^{*}$ and Nawal Aidaros**
}

\begin{abstract}
Objectives: To evaluate the efficiency and stability of Nano seashell, Sodium Fluoride and Signal Complete 8 in treatment of dentine hypersensitivity.

Methods: Forty freshly extracted premolar teeth were collected, disinfected, and sliced into $1.0 \pm 0.1 \mathrm{~mm}$ thickness. The dentin discs were randomly divided into two main groups of 20 discs each. Group 1 $(n=20)$ : Dentin discs subjected to treatment not followed by acid challenge. Group $2(n=20)$ : Dentin discs subjected to treatment followed by acid challenge. Each group was further subdivided into 4 subgroups of 5 discs each according to the treatment used; Subgroup A (Control group): discs received no treatment; Subgroup B: discs treated with Sodium Fluoride paste; Subgroup C: discs treated with Nano Seashell paste; Subgroup D: discs treated with Signal Complete 8 toothpaste. Evaluation of dentinal tubules obliteration was done under scanning electron microscope.
\end{abstract}

Results: There was a significant change in the diameter of tubules and percentage of occlusion for group 1. Group 2 (subjected to acid challenge after treatment) has shown high stability for subgroup B (Sodium Fluoride), followed by subgroup D (Signal Complete 8) then subgroup C (Nano seashell paste).

Conclusion: Nano seashell and Sodium Fluoride caused significant increase of occluded dentinal tubules than Signal complete 8 but the mineral deposits formed by Sodium Fluoride showed higher resistance to acidic environment than those formed by Nano seashell.

KEYWORDS: Dentine hypersensitivity, Nano Seashell, Sodium Fluoride paste, Acid challenge

\footnotetext{
* PhD of Dental Biomaterials Ain Shams University, Lecturer of Dental Biomaterials at Ahram Canadian University.

** PhD Faculty of Dentistry Azhar University, Lecturer of Restorative Dentistry at Ahram Canadian University.
} 


\section{INTRODUCTION}

Dentin hypersensitivity $[\mathrm{DH}]$ is a common encountered dental problem associated with short sharp severe painful clinical condition for which no consistent remedy has been established. The hydrodynamic theory; proposed by Brannstrom M and Astrom A (1966); is the most accepted theory till now ${ }^{[1]}$.

DH is due to patent dentinal tubules that often occurs due to abrasion, attrition, or erosion, causing dentinal fluid movement leading to sharp pain. Dental erosion is one of the major contributing factors in the initiation of dentine hypersensitivity. With increasing consumption of acidic beverages in the modern lifestyle, incidences of dental erosion are becoming more common..$^{[2,3]}$

Currently, the management of DH is based on the concept that occlusion or narrowing of the patent dentinal tubules could effectively reduce dentin hypersensitivity by decreasing dentin permeability decreasing the dentinal fluid movement resulting in reduction of $\mathrm{DH}{ }^{[4,5]}$ Unfortunately, consumption of acidic soft drinks, which is common nowadays, may reverse the dentinal tubules occlusion as acidic substances remove the formed apatite layer ${ }^{[6]}$

The efficacy of the active ingredients contained in toothpastes to occlude dentinal tubules as well as to withstand challenges of acidic beverages became important. Thus, researchers are currently trying to find out active ingredients with high resistance to acidic soft drinks that can achieve stable longlasting dentinal tubules occlusion.

Sodium fluoride, which is a good remineralizing agent, has been widely used as a desensitizer since 1943. However, the chronic ingestion of fluorides in excessive doses may produce enamel fluorosis ${ }^{[7]}$. But the induced crystals are not proven to be resistant to removal through the action of saliva, brushing, or food substances. Moreover, various toothpastes and mouthwashes that can seal or occlude the dentinal tubules are available in the market, they are easy to use, inexpensive and could be applied easily at home. ${ }^{[8]}$
Hydroxyapatite powder is one such material that exhibits excellent bioactive properties and striking similarities to dental hard tissues can be achieved from two different sources. Synthetic and natural (biologic) hydroxyapatite ${ }^{[9-11]}$. HAP can be produced from coral seashells, eggshells, and also from body fluids ${ }^{[12]}$. The traditional way of obtaining synthetic HAP is performed using expensive reagent chemicals; those synthetic routes are costly and time-consuming ${ }^{[13,14]}$.

Recently, the use of waste materials to synthesize HA has received great response from many researchers across the world. This idea gives an innovation to produce a new valuable product from the waste materials such as seashell ${ }^{[15]}$. Seashell consists of high source of calcium that can act as calcium precursor. Some researcher found that the content of calcium carbonate $\left(\mathrm{CaCO}_{3}\right)$ in seashell is approximately between 98 and $99 \%{ }^{[16]}$.

The word seashell is often used to mean only the shell of a marine mollusk. Using seashell as source of calcium carbonate $\left(\mathrm{CaCO}_{3}\right)$ to produce calcite nanoparticle is meaningful for both environmental protection and biomedical application. Seashells with the natural ceramic structure are similar to human bone and tooth structure. ${ }^{[17]}$

The conversion of macroparticles into nanoparticles resulted in larger surface area increasing the reactivity of nanoparticles and hence, its efficacy. Nanoparticles have widespread use due to their superior properties and are being investigated extensively in recent years due to their advantages. Nanoparticulate toothpastes have been demonstrated its optimal effectiveness in the treatment of DH [18]. Nano-sized materials can enter dentinal tubules of $2-3 \mu \mathrm{m}$ diameters easily, occluding the dentinal tubule. ${ }^{[19-21]}$

Thus, the ability to combine the advantage of remineralization and reactivity together with stability in the oral environment would be a target for complete management of the DH. 
Therefore, the aim of the current study is to evaluate and compare the dentinal tubules occluding capacity and the acid resistance of nano seashell particles, Sodium fluoride and a commercially available desensitizing toothpaste (Signal Complete 8) invitro.

\section{MATERIALS AND METHODS}

\section{A) Specimen preparation}

Forty premolar teeth freshly extracted for orthodontic purposes were collected. The collected teeth were subsequently cleaned and disinfected in $10 \%$ chloroxylenol solution. 40 dentin discs of $1.0 \pm 0.1 \mathrm{~mm}$ thickness were prepared by sectioning perpendicular to the long axis of the teeth below the dentino-enamel junction using a low-speed diamond saw under water cooling conditions. ${ }^{[22]}$

Subsequently, wet grounding of the prepared discs was performed using silicon carbide polishing papers $(600-1,000$ grits) for 60 seconds then the discs were polished by polishing stone to obtain a uniform smooth surface. ${ }^{[23]}$

The discs were placed in a jar of distilled water to remove the polishing abrasive. The dentinal tubules were further opened by application of $17 \%$ EDTA gel for 35 seconds; afterwards, they were sonicated in deionized water for 1 minute to clean up all the remnants. ${ }^{[24]}$

\section{B) Specimen grouping}

The prepared dentin discs $(n=40)$ were randomly assigned into two main groups: Group $1(n=20)$ : No acid attack challenge. Group $2(n=20)$ : Acid attack challenge

Each group was subdivided into 4 subgroups according to the test agent used:

Subgroup A: discs received no treatment; Control group $(n=5)$

Subgroup B: discs treated with Sodium Fluoride $(\mathrm{NaF})$ paste $(\mathrm{n}=5)$
Subgroup C: discs treated with Nano Seashell paste $(n=5)$

Subgroup D: discs treated with Signal Complete 8 toothpaste $(n=5)$

\section{C) Testing agents}

\section{Sodium Fluoride Preparation:}

Sodium Fluoride powder $(\mathrm{NaF})$ purchased from PIOCHEM, Egypt Cas no.7681-49-4, Molecular Weight:41,99 was used to prepare NaF paste diluted with distilled water with ratio 1:1.

\section{Nano Seashell Particles Preparation and Characterization}

Cockleshells were collected from Red sea beaches in Egypt. The seashells were washed to remove all dirt. 100 grams seashells were boiled at $100^{\circ} \mathrm{C}$ for 30 minutes and dried for 2 days at $110^{\circ} \mathrm{C}$ in the oven. The shells were then grounded using agate mortar. The dried powder was milled using ball mill machine (planetary-ball-mill-pm-400) for 10 hours, speed $350 \mathrm{rpm}$ and 3 minutes intervals. The obtained seashell nano powder was then dispersed while stirring in distilled water $(10 \% \mathrm{w} / \mathrm{v})$; then carboxymethyl cellulose $(4 \% \mathrm{w} / \mathrm{v})$ was gradually added to the suspension. Finally, the suspension turned to gel form of nano seashell. ${ }^{[25]}$

The Microscopic analysis: Transmission Electron Microscope (TEM) was used to observe the particle size, shape, and distribution of nano seashell particles. The Microscopic analysis was performed on JEOL JEM-2100 high resolution TEM at an accelerating voltage of $200 \mathrm{kV}$, respectively. Energy Dispersive X-ray Analysis (EDX) of Nano Seashell powder was performed to identify the elemental composition of Nano Seashell particles. The standard EDX spectra were recorded on the examined Nano Seashell powder. ${ }^{[26]}$

\section{X-Ray Diffraction analysis (XRD):}

An XRD pattern has been performed using the XPERT-PRO Powder Diffractometer system, with 
2 theta $\left(20^{\circ}-80^{\circ}\right)$, with Minimum step size 2 Theta: 0.001 , and at a wavelength $(\mathrm{K} \alpha)=1.54614 .{ }^{[26]}$

\section{Signal Complete 8}

Toothpaste ingredients: aqua (water), sorbitol, hydrated silica, peg-32, zinic citrate, soduim lauryl sulfate, aroma (flavour), cellulose gum, sodium fluoride, sodium saccharin, mica, ci 77491.

\section{Demineralizing Solution used in the Acid at- tack challenge}

Pepsi Soft drink with $2.49 \mathrm{pH}$ was used (For each $100 \mathrm{ml}$ : sodium $30 \mathrm{mg} 1 \%$, potassium $10 \mathrm{mg}$,

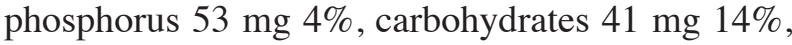
citric acid $5 \%)$. ${ }^{[27]}$

\section{E. Artificial saliva}

The artificial saliva contained (mmoles/l): Distilled water $(700 \mathrm{ml}), \mathrm{CaOH} 2(1.56 \mathrm{mM}), \mathrm{KCl}$ (150.00 mM), HCl (36.00 mM), H3PO4 (0.88 mM), buffer $(99.7 \mathrm{mM}), \mathrm{pH}$ 7.2. ${ }^{[28]}$

\section{F. Treatment of samples}

The discs in each subgroup were embedded in a pre-prepared foam-based container filled with artificial saliva $(10 \mathrm{ml})$ to simulate the oral conditions. Each container was labelled according to the treatment procedure and the agent used.

For group 1(No acid challenge); subgroup A received no treatment, subgroups $\mathrm{B}, \mathrm{C}$ and $\mathrm{D}$ were treated with Sodium fluoride $(\mathrm{NaF})$ paste, Nano seashell paste and signal Complete 8 paste respectively. The paste was rubbed on the sample surface using a micro brush for 2 minutes after which they were rinsed with deionized water for 30 seconds and then stored in the container filled with artificial saliva at $37^{\circ} \mathrm{C} .{ }^{[29]}$ This treatment procedure was repeated every 12 hours for 14 days ${ }^{[30,31]}$. The artificial saliva was changed every 24 hours.

For Group 2 (Acid challenge); the subgroups (B, C, D) were treated with the same test agents ( $\mathrm{NaF}$ paste, Nano Seashell paste and signal Complete 8 paste). The samples of subgroups A, B, C, D were then immersed in the demineralizing solution $(10 \mathrm{ml})$ in petri dish for 30 minutes. Finally, all samples were rinsed in distilled water for 2 minutes to remove the acid before returning to its labelled containers, this process was repeated every 12 hours for 14 days.

\section{G. SEM assessment: Evaluation of dentinal tu- bules occlusion}

Samples were coated with a layer of gold prior to SEM assessment in a Quick Coater vacuum evaporator (Type SC-701; Sanyu Electron Co., Tokyo, Japan) to prevent build-up of electrostatic charge. ${ }^{[32]}$

Evaluation of dentinal tubules occlusion was done using Field Emission-Scanning Electron Microscope (FE-SEM) (QUANTA FEG250) accelerated voltage at $20 \mathrm{KeV}$, Holland.

Dentinal tubules occlusion was calculated by dividing the area of occluded tubules by the total tubules area. Areas of the dentin were imaged in each dentin section. At least three representative SEM micrographs were acquired at $\times 2000$ magnification (three images per disc quarter). the visual standard grading was done by two blinded observers scored the occluded tubules as follows: $1=$ occluded, 2 $=$ partially un occluded, 3 = equally occluded/un occluded, $4=$ mostly occluded, $5=$ unoccluded and the mean score was calculated for each sample.

The percentage of completely occluded tubules was determined by using the following equation:

Number of completely occluded dentinal tubules after treatment / Number of patent dentinal tubules before any treatment X100. ${ }^{[6]}$

To confirm the reliability of scoring, image analysis was performed by a computer software (Image J-Fiji program) that graded all images, and these results were then compared with the results of the visual ordinal scale. 


\section{H. Statistical analysis:}

Data management and statistical analysis were performed using the Statistical Package for Social Sciences (SPSS) version 18. Numerical data were summarized using means, standard deviations, standard error and confidence intervals. Data were explored for normality by checking the data distribution and using Kolmogorov-Smirnov and Shapiro-Wilk tests.

Comparisons between groups with respect to normally distributed numeric variables were done using the one-way analysis of variance (ANOVA test), followed by Tukey's post hoc test for pairwise comparisons. Comparison of the same agent (with / without acid challenge) was performed using paired $\mathrm{t}$ test. All p-values are two-sided. P-values $\leq 0.05$ were considered significant.

\section{RESULTS}

\section{A) TEM-EDX Results}

TEM analysis confirmed the presence of the orthorhombic crystal system of the prepared seashell powder nanoparticles with the particle size ranged from 7.72 to $17.54 \mathrm{~nm}$ as shown in Figure 1. The weight $\%$ and quantitative results of EDX spectrum of Nano Seashell powder are shown in Table 1.

\section{B) XRD results}

The XRD pattern of seashell powder suggested the presence of aragonite crystals. The cockle seashell powder was formed with good quality of calcium carbonate $\left(\mathrm{CaCO}_{3}\right)$. The contained calcium carbonate was found in the aragonite phase. Aragonite has its greatest peak 221 at relatively small ${ }^{\circ} 2 \Theta$. (Fig. 2,Table 1).

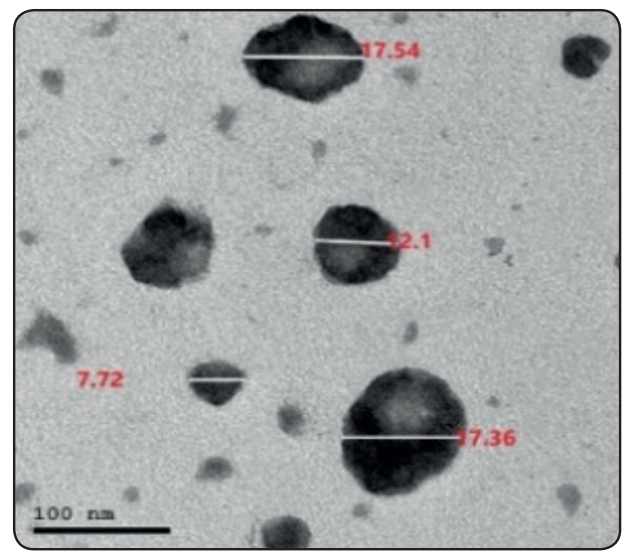

Fig. (1) TEM nanographs for Nano Seashell particles.

Table (1): Showing the weight $\%$ and quantitative results of EDX spectrum of Nano Seashell powder

\begin{tabular}{cccc}
\hline Element & Weight $\%$ & Atomic $\%$ & Error \% \\
\hline $\mathrm{C} \mathrm{K}$ & 4.81 & 8.29 & 19.52 \\
$\mathrm{O} \mathrm{K}$ & 54.01 & 69.92 & 11.51 \\
$\mathrm{Na} \mathrm{K}$ & 1.32 & 1.19 & 30.62 \\
$\mathrm{Ca} \mathrm{K}$ & 39.86 & 20.6 & 1.54 \\
\hline
\end{tabular}

C: Carbon, O: Oxygen, Na: Sodium, Ca: Calcium.

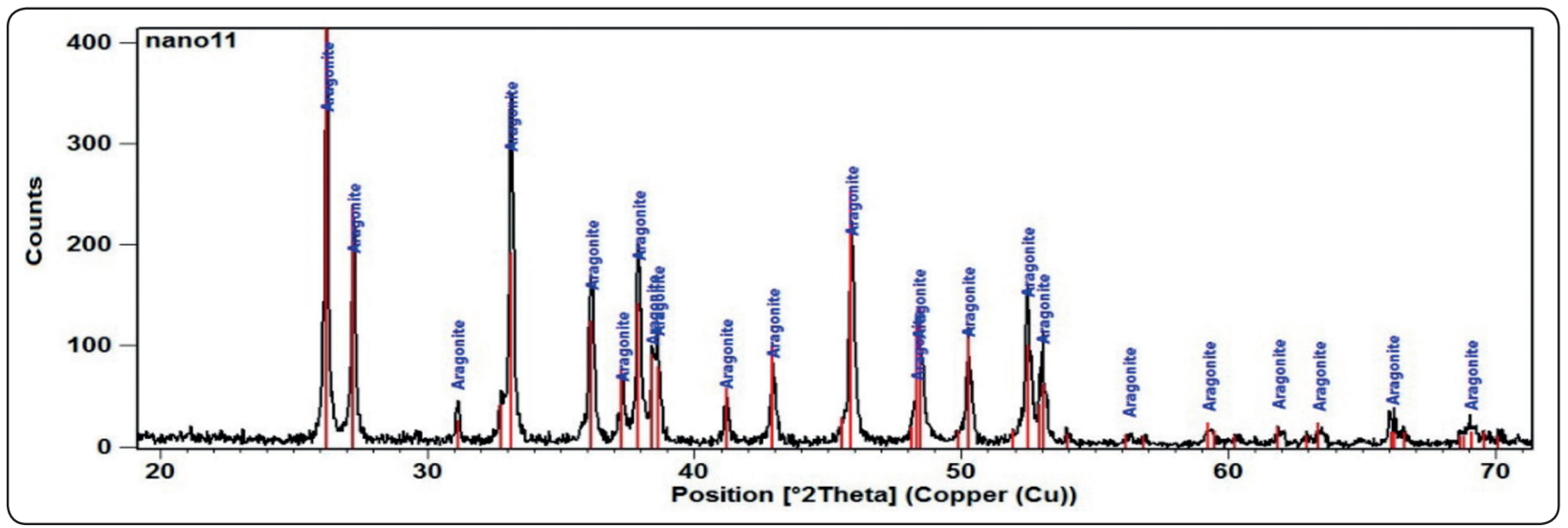

Fig. 2: XRD showing aragonite phase of $\mathrm{CaCo} 3$ 


\section{SEM results: Occlusion of dentinal tubules}

\section{Comparison of \% of occluded dentinal tubules using different agents:}

No acid challenge group (Group 1): The highest mean value was recorded in $\mathrm{NaF}$ group (88.2 \pm 1.30$)$, followed by seashell group (84.6 \pm 2.8$)$, then Signal group (51.6 \pm 2.8$)$, with the least value recorded in Control group (35.4 \pm 2.41$)$. ANOVA test revealed that the difference between groups was statistically significant $(\mathrm{p}=0.00)$. Tukey's post hoc test revealed no statistically significant difference between $\mathrm{NaF}$ and seashell groups, but both groups were significantly higher than signal complete 8 group (Fig.3\& 4, Table 2)

Acid challenge group (Group 2): The highest mean value was recorded in $\mathrm{NaF}$ group (82 \pm 2.35$)$, followed by Signal group (42.6 \pm 3.36$)$, then seashell group (30.2 \pm 3.03$)$, with the least value recorded in Control group (17.6 \pm 1.14$)$. ANOVA test revealed that the difference between groups was statistically significant ( $\mathrm{p}=0.00)$. Tukey's post hoc test revealed a statistically significant difference between each 2 groups (Fig.3\&4, Table 2)

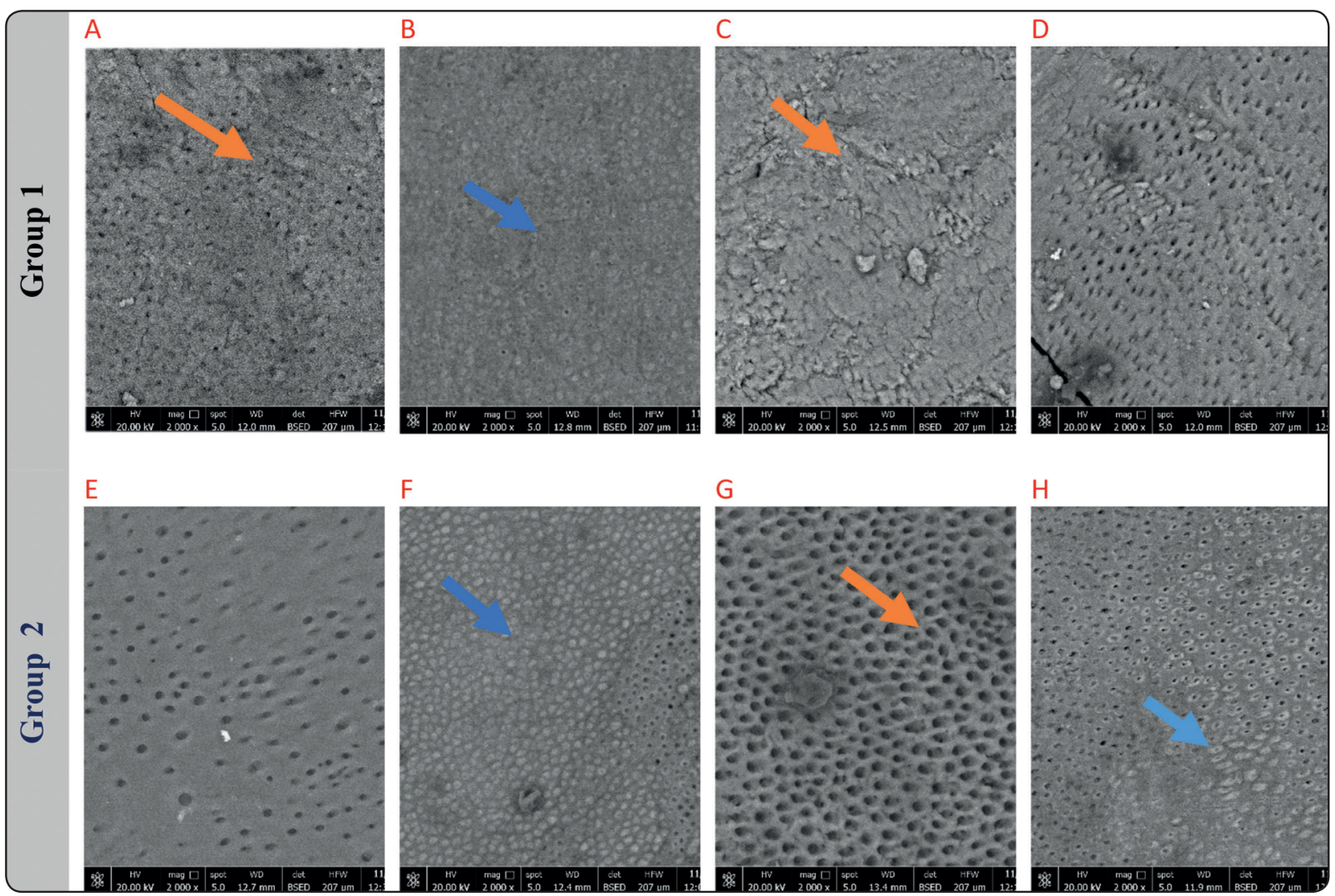

Fig. (3): Representative SEM micrograph for dentine surface after treatment with different groups with 2000 magnification, Group 1: representing the group before acid attack; (A: Control group, B:Na F, C: Nano Seashell, D: Signal complete 8 ). Group 2: representing the group after acid attack: (E: Control group, F: Na F , G: Nano Seashell, H: Signal complete 8 ), the red arrows refers toward the completely opened tubules, while the blue arrows refers to the tubules considered completely obliterated. 
TABLE (2): Descriptive statistics and comparison of $\%$ of occluded dentinal tubules using different agents (ANOVA test)

\begin{tabular}{|c|c|c|c|c|c|c|c|c|c|c|}
\hline & \multirow{2}{*}{ Mean } & \multirow{2}{*}{ Std. Dev } & \multirow{2}{*}{$\begin{array}{l}\text { Std. } \\
\text { Error }\end{array}$} & \multicolumn{2}{|c|}{$\begin{array}{l}95 \% \text { Confidence } \\
\text { Interval for Mean }\end{array}$} & \multirow{2}{*}{ Min } & \multirow{2}{*}{ Max } & \multirow{2}{*}{$\mathrm{F}$} & \multirow{2}{*}{$\mathrm{P}$} \\
\hline & & & & & $\begin{array}{l}\text { Lower } \\
\text { Bound }\end{array}$ & $\begin{array}{l}\text { Upper } \\
\text { Bound }\end{array}$ & & & & \\
\hline \multirow{4}{*}{$\begin{array}{c}\text { Acid } \\
\text { challenge }\end{array}$} & Control & $17.60^{\mathrm{d}}$ & 1.14 & .51 & 16.18 & 19.02 & 16.00 & 19.00 & 569.02 & $0.00 *$ \\
\hline & $\mathrm{NaF}$ & $82.00^{\mathrm{a}}$ & 2.35 & 1.05 & 79.09 & 84.91 & 78.00 & 84.00 & & \\
\hline & Seashell & $30.20^{\mathrm{c}}$ & 3.03 & 1.36 & 26.43 & 33.97 & 25.00 & 32.00 & & \\
\hline & Signal & $42.60^{\mathrm{b}}$ & 3.36 & 1.50 & 38.43 & 46.77 & 38.00 & 47.00 & & \\
\hline \multirow{4}{*}{$\begin{array}{l}\text { No acid } \\
\text { challenge }\end{array}$} & Control & $35.40^{\mathrm{c}}$ & 2.41 & 1.08 & 32.41 & 38.39 & 32.00 & 38.00 & 547.2 & $0.00^{*}$ \\
\hline & $\mathrm{NaF}$ & $88.20^{\mathrm{a}}$ & 1.30 & .58 & 86.58 & 89.82 & 87.00 & 90.00 & & \\
\hline & Seashell & $84.6^{0} \mathrm{a}$ & 2.88 & 1.29 & 81.02 & 88.18 & 81.00 & 88.00 & & \\
\hline & Signal & $51.6^{\circ} \mathrm{b}$ & 2.88 & 1.29 & 48.02 & 55.18 & 48.00 & 55.00 & & \\
\hline
\end{tabular}

Significance level $p \leq 0.05$, *significant

Tukey's post hoc: Within the same comparison, means sharing the same superscript letter are not significantly different.

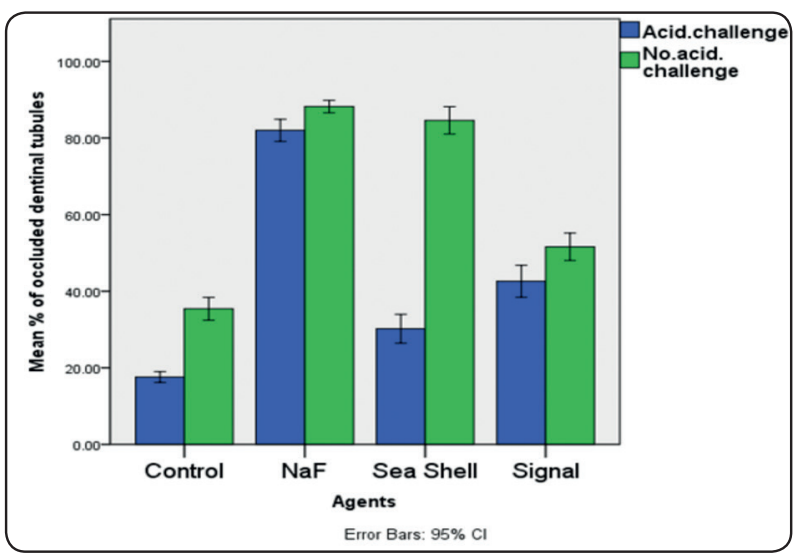

Fig. (4): Bar chart illustrating mean percentage of occluded dentinal tubules using different agents with or without acid attack hallenge.

2. Comparison of $\%$ of occluded dentinal tubules using the same agent with or without acid attack challenge.

Control group: The percentage of occluded dentinal tubules showed a statistically significant higher value without acid challenge group in comparison to with acid challenge (mean difference 17.8 \pm 3.27$),(\mathrm{p}=0.00),($ Table 2$)$
NaF group: The percentage of occluded dentinal tubules showed a statistically significant higher value without acid challenge group in comparison to with acid challenge (mean difference 6.20 \pm 2.49 ), $(\mathrm{p}=0.005)$, (Table 2)

Seashell group: The percentage of occluded dentinal tubules showed a statistically significant higher value without acid challenge group in comparison to with acid challenge (mean difference 54.4 \pm 5.64$),(\mathrm{p}=0.00)$, (Table 2$)$

Signal group: The percentage of occluded dentinal tubules showed a statistically significant higher value without acid challenge group in comparison to with acid challenge (mean difference 9.00 \pm 3.87$),(\mathrm{p}=0.007)$, (Table 2$)$

\section{DISCUSSION}

According to Liu X (2020), Tooth erosion caused by high consumption of acid containing soft drinks is one of major contributing factors of dentin hypersensitivity (DH). Different desensitizing toothpastes and materials have been launched in the market aiming to relieve DH pain by occluding the exposed dentinal tubules to prevent fluid flow. ${ }^{[33]}$ 
Yet Khan AS (2020) Believes that the use of nanomaterials for dentinal tubules occlusion is expected to revolutionize the treatment of $\mathrm{DH}$. Production of nano sized particles enhanced the reactivity as well as surface area as nanoparticles can easily enter dentin tubules. ${ }^{[34]}$ The current study was conducted to evaluate the dentinal tubules occluding capacity and the acid resistance of Nano Seashell, $\mathrm{NaF}$ and a commercially available desensitizing toothpaste invitro (Signal Complete 8).

Although various sources are available for the synthesis of Hydroxyapatite, seashells were chosen in this study owing to its high calcium content, abundance and low cost. The cockle seashell (used in this study) belongs to the species of Anadara granosa, a type of sea molluscan. The cockle seashells are available as a by-product from seafood industry after the mussels were consumed. Cockleshell is one of the abundant sources in $\mathrm{CaCO} 3$ and acts as calcium precursor ${ }^{[20,21]}$.

Acidic Soft drink (Pepsi) was used as demineralizing solution to simulate the effect of soft drinks on tooth causing erosion like lesions ${ }^{[41]}$. SEM was used to analyze the surface of the dentine discs after being treated with the test agents with and without acid challenge.

As claimed by Gergely G et al. (2010), for hypersensitive areas, approximately $75 \%$ of dentin tubules are opened, when inspected under SEM. Nonsensitive cervical dentin show only $24 \%$ of opened dentinal tubules ${ }^{[9]}$.

The samples that did not receive testing agents (subgroups A) showed opened dentinal tubules as shown in fig (4). Evaluation of dentinal tubule occlusion using SEM showed that all the experimental groups produced occlusion of the dentinal tubules, but the extent of coverage and the degree of occlusion varied between the groups. The highest mean value was found in $\mathrm{NaF}$ group (88.2\%) followed by nano seashell (84.6\%) then Signal group (51.6\%).
No statistically significant difference was found between $\mathrm{NaF}$ and nano seashell groups; while the rest of dentinal tubules showed peritubular crystal deposition with subsequently narrowing of dentinal tubules, this could be attributed to that $\mathrm{NaF}$ reacts with the calcium of dentin resulting in the formation of calcium fluoride crystals, which are deposited onto the opening of the dentinal tubules ${ }^{[35]}$.

In agreement with Kunam et al. (2016), the increased tubule occluding efficacy of nano seashell could be attributed to its nanoscale particle size, superior functional properties, and high bioactivity due to its grain size, crystallinity, and surface area to volume ratio in the oral environment compared to its microscale sized counterparts. Since the surface area and proportion of surface atomicity increase with a decrease in particle size, a greater penetration of ion constituents into the dentinal tubules would have occurred that might have resulted in better tubular occlusion ${ }^{[36]}$.

In the current study, mainly aragonite form of calcium carbonate was identified in XRD which was found to be the most biocompatible poly morph of calcium carbonate ${ }^{[37]}$. Our findings confirmed the results found by Awang-Hazmi A et al. (2007), that demonstrated that cockle shell consists of about $96 \% \mathrm{CaCO}_{3}$ whilst other components include organic substances and other oxides like $\mathrm{SiO} 2, \mathrm{MgO}$ and SO3. Cockle shells and coral exoskeletons have similar mineral and physicochemical characteristics to bone and can be used as good optional biomaterial for regeneration ${ }^{[38]}$.

SEM image evaluation of dentin surface treated with $\mathrm{NaF}$ showed $88.2 \%$ completely occluded dentinal tubules. The high mean value of $\mathrm{NaF}$ group could be attributed to the deposition of fluoroapatite crystals in the openings of dentinal tubules leading to its occlusion. Fluoride might act as a catalyst for diffusion of $\mathrm{Ca}$ and $\mathrm{P}$ ions in the dentin surface which aided in remineralization of crystals in the opened dentinal tubules. (fig 4) 
SEM analysis of specimens treated with $2 \% \mathrm{NaF}$ showed narrowing of the dentinal tubular lumen but failed to produce complete tubular occlusion. $\mathrm{NaF}$ reacts with the calcium of dentin resulting in the formation of calcium fluoride crystals, which are deposited onto the opening of the dentinal tubules. However, these crystals are small and hence not effective in occluding the tubules. Similar results were obtained by Raafat A et al. (2011), who showed that fluoride treated specimens displayed significantly lower percentage of tubule occlusion compared to other experimental groups (fig 4). ${ }^{[39]}$

In accordance with this study, Wang $\mathrm{Z}$ et al. (2010) demonstrated that toothpastes containing calcium carbonate had the ability to form a new smear layer on the surface of the dentine that occluded the dentinal tubules. This strongly supports our SEM results after treating the dentin disc with Nano seashell paste ${ }^{[40]}$.

When comparing the percentage of completely occluded dentinal tubules after treatment the samples with the test agents in group 2 (acid challenge group), The highest mean value was recorded in $\mathrm{NaF}$ group (82 \pm 2.35$)$, followed by Signal group (42.6 \pm 3.36 ), then seashell group $(30.2 \pm 3.03)$, with the least value recorded in Control group (17.6 \pm 1.14$)$.

The percentage of occluded dentinal tubules showed a statistically significant higher value without acid challenge (Group 1) in comparison to with acid challenge (Group 2) (mean difference $17.8 \pm 3.27$ ). In the acid challenge group (Group2) SEM image evaluation of dentin surfaces demonstrated peritubular particle depositions and partial coverage of the dentinal tubules, where few dentinal tubules demonstrated complete occlusion along with some unoccluded tubules.

Most tubules in specimens remained partially occluded after the acid attack. However, more unoccluded tubules were seen in the specimens in comparison to no acid groups as shown in figure 4. Opened dentinal tubules after acidic challenge explain the erosive potential of acidic soft drinks like Pepsi that was used in the current study. Murrell S et al. (2010) and Panda A et al. (2017) have reported that carbonated beverages from different countries are potentially erosive, and that erosion increased with increasing duration of exposure. This explains the aggressive effect of Pepsi used as demineralizing solution for $30 \mathrm{~min}$ after treatment with different agent in this study. ${ }^{[41,42]}$

Regarding the effect of the ingredients of the toothpaste used in the current study (Signal Complete 8), White DJ et al. (2007) emphasized that fluoridecontaining toothpaste generates a variety of soluble mineral ions that form an insoluble precipitate, which blocks the open dentine tubules to prevent the entry of stimuli and have a desensitizing effect on $\mathrm{DH}^{[43]}$

Moreover, the results obviously showed that acid resistant characteristics of $\mathrm{NaF}$ was superior to that of signal and nano seashell powder. This could be explained by the resistance of fluorapatite mineral phase to demineralization and acid dissolution. Fluorapatite can reduce enamel and dentine solubility. Fluoride application increase dentine's resistance to erosive challenge as confirmed by Magalhaes AC et al. (2008) And Diamanti I et al. (2010). Moreover, fluoride works when small amounts of fluoride are maintained constantly in our used artificial saliva which enhanced the dentinal tubules occlusion. ${ }^{[4,45]}$

Regarding Nano seashell subgroup in acid challenge group (group 2); this study showed its low resistance to the acid attack and the washing away of the formed layer seen in group 1 .

Occluding agents stated by many articles are strontium salts, calcium carbonate, calcium hydroxide, stannous hydroxide, calcium oxalate and ferric phosphate etc. But these materials are proven to be effective only for short time because they are rinsed away by the saliva and water. ${ }^{[46]}$ 
Park Y et al. (2014) affirmed that calcium carbonate has a long-lasting effect on dentinal tubules occlusion depends on Ca-ion binding polymers, that ensure high stability after washing. That is because teeth are composed of hydroxyapatite that is abundant with Ca-ions. So, the Ca-ion binding polymers such as sodium alginate, gellan gum, carrageenan gum, and polyglutamic acid etc would adhere to the surface of the teeth and calcium carbonate abrasives. Those polymers could be the bridge between the teeth and abrasives ${ }^{[47]}$ This study did not include any of the previous polymers that may explain the wash away of the formed layer after exposure to demineralizing solution used in the current study.

\section{CONCLUSION}

Under the limitations of this invitro study it was concluded that:

1. Soft drink as Pepsi causes demineralization of dentin surfaces. The study confirmed the erosive potential of Pepsi.

2. Cockle seashell consists mainly of aragonite form of calcium carbonate $(\mathrm{CaCo} 3)$ and could be used as good source of calcium.

3. The efficacy of nano seashell and $\mathrm{NaF}$ to occlude the opened dentinal tubules is demonstrated.

4. The mineral deposits in the dentinal tubules openings formed by $\mathrm{NaF}$ and Signal complete 8 showed higher resistance to acid environment (Pepsi) than those formed by Nano seashell.

\section{RECOMMENDATION}

Further studies are recommended to compare the dentinal occluding efficiency of Nano seashell alone and Nano seashell combined with one of the Ca-ion binding polymers that act as bridge between $\mathrm{CaCo} 3$ and $\mathrm{Ca}$ ions in tooth structure.

\section{REFERENCES}

1. Brannstrom M, Astrom A. The hydrodynamics of the dentine, its possible relationship to dentinal pain. . DentIstry journal. 1972;22:219-27.

2. West N, Hughes J, Addy M. Erosion of dentine and enamel in vitro by dietary acids: the effect of temperature, acid character, concentration and exposure time. Journal of oral rehabilitation. 2000;27(10):875-80

3. Stefański T, Postek-Stefańska L. Possible ways of reducing dental erosive potential of acidic beverages. Australian Dental Journal. 2014;59(3):280-8.

4. Hiller K-A, Buchalla W, Grillmeier I, Neubauer C, Schmalz G. In vitro effects of hydroxyapatite containing toothpastes on dentin permeability after multiple applications and ageing. Journal of scientific reports. 2018;8(1):1-13.

5. Parolia A, Kundabala M, Mohan M. Management of dentinal hypersensitivity: a review. Journal of California Dental Association. 2011;39(3):167-79.

6. Bakri MM, Hossain MZ, Razak FA, Saqina Z, Misroni A, Ab-Murat N, Kitagawa J, Saub R. Dentinal tubules occluded by bioactive glass-containing toothpaste exhibit high resistance toward acidic soft drink challenge. Australian Dental Journal. 2017;62(2):186-91.

7. DenBesten P, Li W. Chronic fluoride toxicity: dental fluorosis. Fluoride and the oral environment. 22: Karger Publishers; 2011.p. 81-96.

8. Wetton S, Hughes J, Newcombe RG, Addy M. The effect of saliva derived from different individuals on the erosion of enamel and dentine. Journal of Caries research. 2007;41(5):423-6.

9. Gergely G, Wéber F, Lukács I, Illés L, Tóth A, Horváth Z, Mihály J, Balázsi C. Nano-hydroxyapatite preparation from biogenic raw materials. Journal of Open Chemistry. 2010;8(2):375-81.

10. Mezahi F-Z, Oudadesse H, Harabi A, Le GY, Cathelineau G. Sintering effects on physicochemical properties of bioactivity of natural and synthetic hydroxyapatite. Journal of the Australasian Ceramic Society. 2011;47(1):23-7.

11. Barros M, Bello P, Bao M, Torrado J. From waste to commodity: transforming shells into high purity calcium carbonate. Journal of Cleaner Production. 2009; 17(3):400-7. 
12. Ripamonti CI, Maniezzo M, Campa T, Fagnoni E, Brunelli C, Saibene G, Bareggi C, Ascani L, Cislaghi E. Decreased occurrence of osteonecrosis of the jaw after implementation of dental preventive measures in solid tumour patients with bone metastases treated with bisphosphonates. The experience of the National Cancer Institute of Milan. Annals of Oncology journal,. 2009;20(1):137-45.

13. Szcześ A, Hołysz L, Chibowski E. Synthesis of hydroxyapatite for biomedical applications. Journal of Advances in colloid and interface science. 2017;249:321-30.

14. Fara DG. Names are predicates. Philosophical Review. 2015;124(1):59-117.

15. Santhosh S, Prabu SB. Thermal stability of nano hydroxyapatite synthesized from sea shells through wet chemical synthesis. Materials Letters journal,. 2013;97:121-4.

16. Lee C-H, Orloff ND, Birol T, Zhu Y, Goian V, Rocas E, Haislmaier R, Vlahos E, Mundy JA, Kourkoutis LF. Exploiting dimensionality and defect mitigation to create tunable microwave dielectrics. Journal of Nature. 2013; 502(7472):532-6.

17. H Silva T, Mesquita-Guimarães J, Henriques B, Silva FS, Fredel MC. The potential use of oyster shell waste in new value-added by-product. Journal of Resources. 2019;8(1):13.

18. Yu J, Yang H, Li K, Lei J, Zhou L, Huang C. A novel application of nanohydroxyapatite/mesoporous silica biocomposite on treating dentin hypersensitivity: An in vitro study. Journal of dentistry. 2016;50:21-9.

19. Onwubu SC, Mdluli PS, Singh S. The Effectiveness of Nanomaterials in the Management of Dentine Hypersensitivity-A. Journal of Clinical Review \& Case Reports, 2018;3(8):5.

20. Tian L, Peng C, Shi Y, Guo X, Zhong B, Qi J, Wang G, Cai Q, Cui F. Effect of mesoporous silica nanoparticles on dentinal tubule occlusion: An in vitro study using SEM and image analysis. Dental materials journal. 2014; 33(1):125-32.

21. Onwubu SC, Mdluli PS, Singh S. The Effectiveness of Nanomaterials in the Management of Dentine Hypersensitivity-A. Journal of Clinical Review \& Case Reports, 2018.

22. Wang W, Liu Y, Yang C, Qi X, Li S, Liu C, Li X. Mesoporous bioactive glass combined with graphene oxide scaffolds for bone repair. International journal of biological sciences. 2019;15(10):2156.
23. Yang J-C, Hu H-T, Lee S-Y, Hsieh S-C, Huang P-C, Ma C-F, Ji D-Y, Chang L-Y, Teng N-C. In vitro evaluation of dentin tubule occlusion for novel calcium lactate phosphate (CLP) paste. Materials journal. 2017;10(3):228.

24. Machado AC, Rabelo FEM, Maximiano V, Lopes RM, Aranha ACC, Scaramucci T. Effect of in-office desensitizers containing calcium and phosphate on dentin permeability and tubule occlusion. Journal of dentistry. 2019;86:53-9.

25. Tram NXT. Synthesis and characterization of calcite nanoparticle derived from cockle shell for clinical application. ASEAN Engineering Journal. 2020;10(1):49-54.

26. Onwubu SC, Mdluli PS, Singh S, Tlapana T. A novel application of nano eggshell/titanium dioxide composite on occluding dentine tubules: an in vitro study. Brazilian oral research journal,. 2019;33.

27. Jeneta JG, Prabakar J. Evaluation of PH and buffering capacity of sports drinks and carbonated drinks. Journal of Drug Invention Today. 2019;11(11).

28. Alhussain AM, Alhaddad AA, Ghazwi MM, Farooq I. Remineralization of artificial carious lesions using a novel fluoride incorporated bioactive glass dentifrice. Journal of Dental and medical problems. 2018;55(4):379-82.

29. Hu M-L, Zheng G, Jiang R-D, Han J-M, Zhang Y-D, Lin $H$. The evaluation of the desensitization effect of a desensitizing agent and desensitizing toothpastes in vitro. Journal of Dental Materials. 2020;39(5):855-61.

30. Saini N, Mathur S, Saini V, Kapoor A, Vijay S, Gurjar S. Effect of commercially available nano-hydroxy apatite containing desensitizing mouthwash on dentinal tubular occlusion: an in vitro FESEM analysis. Medicine and Pharmacy Reports. 2020;93(4):396.

31. George G, Ranjini M, Pai VS, Darsan J, Nadig RR. Evaluation of dentinal tubule occlusion using a desensitizing toothpaste and mouthwash for a period of 60 days: Scanning electron microscopy analysis. Journal of Interdisciplinary Dentistry. 2018;8(3):96.

32. Chen C, Parolia A, Pau A, Celerino de Moraes Porto I. Comparative evaluation of the effectiveness of desensitizing agents in dentine tubule occlusion using scanning electron microscopy. Australian Dental Journal. 2015;60(1):65-72.

33. Liu X-X, Tenenbaum HC, Wilder RS, Quock R, Hewlett ER, Ren Y-F. Pathogenesis, diagnosis and management 
of dentin hypersensitivity: an evidence-based overview for dental practitioners. Journal of BMC Oral Health. 2020;20(1):1-10.

34. Khan AS, Farooq I, Alakrawi KM, Khalid H, Saadi OW, Hakeem AS. Dentin tubule occlusion potential of novel dentifrices having fluoride containing bioactive glass and zinc oxide nanoparticles. Medical Principles and Practice Journal. 2020;29(4):338-46.

35. Orchardson R, Gillam DG. Managing dentin hypersensitivity. The Journal of the American Dental Association. 2006;137(7):990-8.

36. Kunam D, Manimaran S, Sampath V, Sekar M. Evaluation of dentinal tubule occlusion and depth of penetration of nano-hydroxyapatite derived from chicken eggshell powder with and without addition of sodium fluoride: An in vitro study. Journal of conservative dentistry,. 2016;19(3):239.

37. Chen J, Xiang L. Controllable synthesis of calcium carbonate polymorphs at different temperatures. Journal of Powder Technology. 2009;189(1):64-9.

38. Awang-Hazmi A, Zuki A, Noordin M, Jalila A, Norimah Y. Mineral Composition of the Cockle (Anadara granosa) Shells of West Coast of Peninsular Malaysia and It? s Potential as Biomaterial for Use in Bone Repair. Journal of Animal and Veterinary Advances. 2007;6-5.

39. Raafat Abdelaziz R, Mosallam RS, Yousry MM. Tubular occlusion of simulated hypersensitive dentin by the combined use of ozone and desensitizing agents. Acta Odontologica Scandinavica. 2011;69(6):395-400.

40. Wang Z, Sa Y, Sauro S, Chen H, Xing W, Ma X, Jiang T, Wang Y. Effect of desensitising toothpastes on dentinal tubule occlusion: a dentine permeability measurement and SEM in vitro study. Journal of dentistry. 2010;38(5):400-10.
41. Murrell S, Marshall TA, Moynihan PJ, Qian F, Wefel JS. Comparison of in vitro erosion potentials between beverages available in the United Kingdom and the United States. Journal of dentistry. 2010;38(4):284-9.

42. Panda A, Ghosh B, Pal I, Kumar V, Bhuyan L, Dash KC. Dissolution of Enamel on Exposure to Various Commercial Beverages Available in India. The journal of contemporary dental practice. 2017;18(11):1009-13.

43. White DJ, Lawless MA, Fatade A, Baig A, von Koppenfels R, Duschner H, Gotz H. Stannous fluoride/sodium hexametaphosphate dentifrice increases dentin resistance to tubule exposure in vitro. Journal of Clinical Dentistry. 2007;18(2):55.

44. Magalhaes AC, Rios D, Machado MADAM, Da Silva SMBc, Lizarelli RDFtZ, Bagnato VS, Buzalaf MAR. Effect of Nd: YAG irradiation and fluoride application on dentine resistance to erosion in vitro. Journal of Photomedicine and Laser Surgery. 2008;26(6):559-63.

45. Diamanti I, Koletsi-Kounari H, Mamai-Homata E, Vougiouklakis G. Effect of fluoride and of calcium sodium phosphosilicate toothpastes on pre-softened dentin demineralization and remineralization in vitro. Journal of dentistry. 2010;38(8):671-7.

46. Chidchuangchai W, Vongsavan N, Matthews B. Sensory transduction mechanisms responsible for pain caused by cold stimulation of dentine in man. Archives of Oral Biology Journal. 2007;52(2):154-60.

47. Park Y-D, Ahn H-K, Kwon H-J, Kim C-H, Chae S-K, Kim Y-j, Kim W-G, Hwang K-S. Calcium carbonate and sodium chloride for preventing dentin hypersensitivity and gum diseases. International Journal of Clinical Preventive Dentistry. 2014; 10(2):74-86. 